\title{
QU
}

\section{A IMPORTÂNCIA E EFICÁCIA DO ENSINO TRADICIONAL ALIADO A METODOLOGIA CONSTRUTIVISTA NO ENSINO DE CIÊNCIAS/QUÍMICA}

FARIAS, A. L. S.*(IFRN) ; OLIVEIRA, M. M. (IFRN)

\section{RESUMO}

Este trabalho tem por objetivo enfatizar a importância e eficácia do uso da metodologia tradicional no ensino de ciências/química analisando o processo histórico da educação desde os primórdios até os dias atuais. Pretende-se analisar as contribuições desta metodologia e evidenciar a necessidade de falar a respeito desta pelo fato da mesma ser, ainda que considerada ultrapassada, a principal metodologia utilizada por professores desde o ensino básico ao ensino superior em instituições públicas e privadas.

PALAVRAS-CHAVE: METODOLOGIAS NO ENSINO DE CIÊNCIAS/QUÍMICA. METODOLOGIA

\section{THE IMPORTANCE AND EFFECTIVINESS OF THE TRADITIONAL TEACHING ALLY TO THE CONSTRUCTIVIST METHODOLOGY IN SCIENCE/CHEMISTRY TEACHING}

\begin{abstract}
This work aims to emphasize the importance and effectiveness of the use of traditional methodology in the science/chemistry learning, analyzing the historical process of the education since the beginnings until nowadays. It is intended to analyze the contributions of

this methodology and to evidence the need of talking about that because, although it is considered overtaken, it is the main methodology used by teachers since the elementary teaching to graduation teaching in public and private

institutions.
\end{abstract}




\section{A IMPORTÂNCIA E EFICÁCIA DO ENSINO TRADICIONAL ALIADO A METODOLOGIA CONSTRUTIVISTA NO ENSINO DE CIÊNCIAS/QUÍMICA}

\section{INTRODUÇÃO}

As metodologias de ensino são "práticas pedagógicas operacionalizadas por meio de conjuntos de atividades escolares propostas pelos professores com vistas a alcançar a aprendizagem de determinados conhecimentos, valores e comportamentos" (TRAVERSINI; BUAES, 2009, p. 145 apud KRUGER, 2013). Estas servem como um auxílio para o professor desempenhar o seu trabalho com o intuito de contribuir para o aprendizado do aluno em sala de aula e/ou para vida.

Nota-se que devido aos avanços tecnológicos e as mudanças ocorridas desde a década de 50 (fatores políticos, econômicos, sociais, culturais, etc.) a educação em todas as modalidades tem passado por modificações. Estudos das mais diversas áreas mostram as boas consequências que essas mudanças permitiram no ensino, porém há muitos que apontam lacunas que isso ocasionou, visto que a metodologia tradicional antes usada ainda perdura em todas as modalidades de ensino.

Essas lacunas evidenciam o fato dessa metodologia, embora vista como ultrapassada, ser eficiente no processo de ensino-aprendizagem do aluno, pois foram/são os métodos tradicionais os responsáveis pela educação nos primeiros anos de vida acadêmica dos jovens, principalmente em escolas da rede pública que não disponibilizam de muitos recursos.

Sem falar no fato de que muito se tem falado sobre novos métodos didáticos em sala de alua, principalmente na disciplina de química, mas que estes muitas vezes não tem saído do papel. Nota-se que embora seja comprovado a eficácia e os benefícios dessas novas metodologias nada têm substituído a prática do ensino tradicional.

No contexto das metodologias de ensino, mais especificamente na tradicional, pretende-se em contato com alunos e com professores das três modalidades de ensino obter respostas por meio de entrevistas e questionários, para a seguinte questão: 
Segundo a percepção dos alunos e dos professores a construção do conhecimento/ aprendizagem dos conteúdos acadêmicos é possível por meio da metodologia tradicional?

Para responder a esta questão, tem-se como objetivo geral: Identificar a contribuição dos métodos tradicional de ensino no processo de aprendizado do aluno, a partir da percepção de alunos do ensino fundamental, médio e superior e professores dessas três modalidades. E, para alcançar este objetivo, estabeleceu-se quatro objetivos específicos, os quais são: investigar a receptividade dos alunos quanto à prática do uso de metodologias tradicionais de ensino; identificar sobre o ponto de vista do professor a contribuição desta metodologia em suas aulas de ciências/química; evidenciar a eficácia desta aliada ao método construtivista no ensino de alguns conteúdos e enfatizar a importância dessa metodologia como base no ensino.

Nesse trabalho merece destaque também a problemática que o não uso dessa metodologia tradicional em sala de aula tem causado. Dentre os muitos serão destacados dois problemas: A não utilização do livro didático em sala, ferramenta primordial no ensino que tem sido atualmente substituído por uso inadequado da internet e a escrita dos alunos, mostrando que há uma certa dificuldade por parte dos alunos com relação ao desenvolvimento de frases e textos e até mesmo na própria escrita de palavras, mostrando que isso pode ter sido ocasionado em virtude da substituição dessa metodologia por meios que estão deixando os alunos "acomodados" ao encontrarem tudo pronto na internet.

\section{MATERIAIS E MÉTODOS}

Neste trabalho no procedimento técnico será utilizada a pesquisa de campo para adiquirir as informações necessárias sobre o problema da pesquisa, partindo-se primeiro de uma revisão bibliográfica, analisando- se os trabalhos já existentes na área, realizando um plano de trabalho para atender aos objetivos e, por fim, coletar os dados a partir da realização de um questionário.

Em relação à abordagem do problema, enquadra-se como qualitativa e quantitativa, pois irá investigar, descrever, interpretar e analisar, na opinião dos alunos e 4a Semana de Química - IFRN, 2016 
dos professores sobre a contribuição dos métodos, tradicional e construtivista de ensino, bem como a contribuição das diversas metodologias para o aprendizado do aluno tomando por base o pensamento de alguns autores.

Para coleta dos dados, optou-se pelo uso do questionário, pois é uma forma de obter os dados referentes às variáveis e situações que se deseja investigar (VERGARA, 2009 apud KRUGER, 2013). Este será aplicado com os alunos do ensino fundamental, médio e superior e espera-se que por meio deste eles apontem sua opinião sobre as metodologias utilizadas pelos professores.

As questões versarão de conhecimentos específicos da disciplina de ciências/química a metodologias dos professores e recursos utilizados por eles visando identificar a opinião dos alunos sobre as diversas metodologias de ensino, e assim verificar a opinião dos alunos a respeito das metodologias utilizadas durante as aulas de ciências e química.

Além do uso dos questionários para coleta e análise de dados, será realizado com os professores entrevistas, visto que, esta permitirá um melhor contato com os docentes visando que os mesmos falem sobre as experiências vividas na carreira e que demonstrem satisfação ou não sobre o que vivenciaram.

\section{RESULTADOS ESPERADOS}

Espera-se com este trabalho promover dentre os discentes e docentes uma reflexão sobre as metodologias de ensino especificamente sobre o método tradicional para que no exercício da função sejam adotadas melhores práticas visando uma melhor conduta dos conteúdos da disciplina de ciências/química. Pretende-se também mostrar que a metodologia tradicional precisa ser vista sob um novo olhar, dado que esta é vista atualmente como uma forma de ensino-aprendizagem ultrapassada, mas que não perdeu sua eficácia e perdura em muitas instituições de ensino que não disponibilizam de recursos.

Pretende-se ne trabalho, mediante estudos, observações e coleta de dados constatar que de fato a metodologia tradicional se faz presente no ensino de 
ciências/química, e que essa tem se mostrado tão eficiente e eficaz na aprendizagem dos alunos como as outras metodologias consideradas inovadoras.

Por fim, almeja-se contribuir para formação de discentes e docentes no que diz respeito a escolha de metodologias a serem adotadas em sala de aula que condizam com a realidade de cada um mostrando que, de modo particular, a prática tradicional se encaixa no contexto de muitas escolas, inclusive as públicas que não desfrutam de muitos recursos, e que permitem que o aluno de qualquer instituição possa ter um bom rendimento na disciplina de ciências/química.

\section{REFERÊNCIAS}

KRUGER, Letícia M. ENSSLIN, Sandra R: Método Tradicional e Método Construtivista de Ensino no Processo de Aprendizagem: uma investigação com os acadêmicos da disciplina Contabilidade III do curso de Ciências Contábeis da Universidade Federal de Santa Catarina. Organizações em contexto, São Bernardo do Campo, ISSNe 1982-8756. Vol. 9, n. 18, jul-dez. 2013. p. 220- 270.

LEÃO, Denise M. Maciel: Paradigmas contemporâneos de Educação: Escola Tradicional e Escola Construtivista. Caderno de Pesquisa, no 107, p. 187-206, julho/1999. p.187- 206.

LIMA, Juliane S.: Metodologia no Ensino de Ciências. 11 de junho de 2006. 34 folhas. Trabalho de Conclusão de Curso de Licenciatura em Biologia - Universidade de Brasília, Brasília 2011.

PROTETTI, Fernando H.: Afinal, existe algum aspecto positivo no modelo da Escola Tradicional? 6 COLÓQUIO INTERNACIONAL MARX E ENGELS.

SAVIANI, Demerval: As concepções pedagógicas na história da Educação Brasileira. Campinas, 25 de agosto de 2005. 